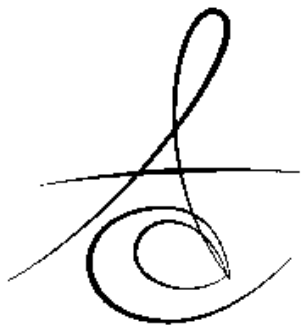

\title{
AŞIRI MADDE KAYBINA UĞRAMIŞ ENDODONTİK TEDAVİLİ MAKSİLLER ÖN DİŞLERİN CAD/CAM YÖNTEMİYLE TEK SEANSTA ESTETÍK RESTORASYONU: 2 VAKA SUNUMU
}

\section{CHAIRSIDE ESTHETIC REHABILITATION OF ENDODONTICALLY TREATED MAXILLARY ANTERIOR TEETH WITH EXTENSIVE LOSS OF TOOTH STRUCTURE USING CAD/CAM SYSTEM: REPORT OF TWO CASES}

\author{
Öğr. Gör. Dr. Merve BANKOĞLU GÜNGÖR* \\ Arș. Gör. Aylin DOĞAN*
}

\author{
Doç. Dr. Seçil KARAKOCA NEMLİ \\ Arş. Gör. İrem KARADAĞ*
}

Makale Kodu/Article code: 2222

Makale Gönderilme tarihi: 31.03 .2015

Kabul Tarihi: 11.06.2015

\section{ÖZET}

Kron kısmında fazla madde kaybı olan endodontik tedavili dişlerin protetik restorasyonunda uzun yıllardır, kök kanallarından destek alan post-kor restorasyonları kullanılmaktadır. Post-kor restorasyonların başarısı uygulama tekniğinin yanı sıra kullanılan post materyalleri ve restorasyon materyalleri ile de yakından ilişkilidir. Günümüzde gelişen Bilgisayar destekli tasarım/ Bilgisayar destekli üretim (CAD/CAM) teknolojisi ile post-kor restorasyonları farklı seramiklerden tek seansta ve tek parça olarak uygulanabilmektedir. CAD/CAM cihazlarında işlenmeye uygun ve yapısal farklılıklar gösteren yeni materyallerin post-kor restorasyonlarında kullanımı, bu restorasyonların başarısı için önem taşımaktadır. Bu sayede aşırı harap olmuş dişlerin; çok kısa sürede, düşük maliyet ve yüksek uyumlu restorasyonlarla uzun süre hizmet vermesinin sağlanabileceği düşünülmektedir. Bu vaka sunumunda; aşırı madde kaybına uğramış endodontik tedavili maksiller ön dişlerin, tek seansta hem post-kor hem de kron restorasyonunun CAD/CAM sistemiyle tamamlandığı estetik restorasyonlarının sunulması amaçlanmaktadır. 1. vakada; üst sağ santral dişten geleneksel yöntemlerle alınan ölçü ekstraoral tarayıcıda dijital olarak taranarak CAD yazılımına aktarıldı, post-kor ve kron restorasyonu sanal modeller üzerinde ayrı ayrı tasarlandı ve her iki yapı lityum disilikat materyalinden üretilerek dişe simante edildi. 2. vakada; çok geniş bir kanala sahip üst sol lateral diş ile komşu ve karşıt dişlerden intraoral tarayıcı ile dijital ölçü alındı, post-kor ve kron restorasyonu sanal modeller üzerinde ayrı ayrı tasarlandı ve post-kor rezin nanoseramik materyalinden, kron ise lityum disilikat materyalinden üretildi. İki vakada CAD/CAM sistemi ile farklı üretim yöntemi ve farklı materyaller kullanılmakla beraber tek seansta restorasyonlar tamamlanarak tedavi süresi kısaltıldı ve estetik açıdan tatmin edici restorasyonlar yapıldı. Her iki vakanın da 1 yıllık takipleri sonucunda herhangi bir komplikasyon kaydedilmedi ve yüksek hasta memnuniyeti gözlendi.

Anahtar Kelimeler: Kök Çivisi Tekniği, Bilgisayar yardımlı tasarı, Lityum disilikat

\section{ABSTRACT}

Post-core restorations supported by root canals have been generally used for decades in rehabilitation of endodontically treated teeth have insufficient tooth structure. Success of post-core restorations are closely related with post and restorative materials as well as application techniques of the restorations. With the recent development of computer aided design and computer aided manufacturing (CAD/CAM) technology, post-core retorations can be chairside and one-piece which fabricated from different restorative materials. Using new different materials which can be milled in CAD/CAM devices for rehabilitation of post-core restorations is important for the success of these restorations. This technology enables the fabrication of low cost, time consuming and accurate fitted restorations which can be fabricated to ensure the long term service. In this clinical report, the restoration of endodontically treated anterior maxillary teeth with extensive loss with chairside CAD/CAM system. In the first case, impressions which were taken with conventional methods from the upper right central tooth was scanned in extraoral scanner and transferred to CAD software. Post-core and crown restorations were separately designed in virtual models, fabricated from lithium disilicate material and cemented. In the second case, digital impressions which were taken with intraoral scanner from the upper left lateral and adjacent teeth. Post-core was fabricated from resin nanoceramic and the crown was fabricated from lithium disilicate material. In both two cases, time-consuming and satisfactory chairside restorations were fabricated using different CAD/CAM methods and materials. No complication was observed during the 1-year follow-up and the patients were satisfied.

Key Words: Post and Core Technique, Computer-Aided Design, Lithia disilicate

\footnotetext{
* Gazi Üniversitesi, Diş Hekimliği Fakültesi, Protetik Diş Tedavisi AD.
} 
Atatürk Üniv. Diş Hek. Fak. Derg.

J Dent Fac Atatürk Uni

Cilt:26, Sayı:1, Yıl: 2016, Sayfa: 133-138

Aşırı madde kaybına uğramış endodontik tedavili dişlerde yapılacak protetik restorasyona tutuculuk sağlamak ve restorasyonu güçlendirmek amacıyla genellikle post-kor uygulaması yapılmaktadır. ${ }^{1,2}$ Diş hekimliği pratiğinde günümüze kadar kullanılmış materyal ve yapım yöntemi açısından farklılıklara sahip çok sayıda post ve kor türü bulunmaktadır. ${ }^{1}$ Post-kor restorasyonları diş hekimliğinde en çok üzerinde çalışılan konular arasında yer almasına rağmen ideal post-kor materyali ve tekniği konusunda fikir birliği sağlanamamıştır. ${ }^{3,4}$ Endodontik tedavili ön bölge dişlerinde uygun restorasyon seçiminde dayanıklılığın yanı sıra estetik özellikler de önem taşımaktadır. ${ }^{5}$ Ön bölge dişlerinin protetik tedavisinde genellikle ışık geçirgenliği özellikleri sayesinde estetik açıdan en iyi sonucu sağlayan tam seramik restorasyonlar tercih edilmektedir. ${ }^{1}$ Ancak materyalin ışık geçirgenliği restorasyonun renginin, altındaki diş veya kor yapının renginden etkilenmesine neden olmaktadır. ${ }^{5}$ Bu sebeple endodontik tedavili dişlerde tam seramik restorasyonlar ile beraber uzun yıllar yaygın olarak uygulanmış metal postlar yerine estetik post ve korların kullanımı gündeme gelmiştir. Estetik post ve korlar iyi bir estetik sağlamanın yanı sıra korozyon ve toksisite riskini azaltmaları gibi avantajlara sahiptirler. Estetik restorasyonlara destek sağlamak amacıyla zirkonya, seramik, fiber ile güçlendirilmiş rezin, kompozit rezin gibi diş rengine uygun materyallerden yapılmış post ve kor türleri geliştirilmiştir. Kişisel olarak hazırlanan post ve korların çok geniş, dairesel olmayan veya silindirik yapıdaki ve prefabrike postların adaptasyon sağlayamayacağı aşırı konik kanallar için endikasyonu bulunmaktadır. ${ }^{6}$ Ayrıca dişteki madde kaybının çok fazla olduğu durumlar kişisel postların kullanımını gerektirmektedir. $^{5}$ Estetik restoratif materyallerden kişisel post-kor hazırlanması CAD/CAM teknolojisindeki gelişmeler ile gündeme gelmiştir. ${ }^{7}$ CAD/CAM yöntemi ile kişisel olarak hazırlanan, zirkonya ${ }^{8-10}$ ve cam fiber ile güçlendirilmiş kompozit rezin ${ }^{11}$ post-korlar üretilmiştir. CAD/CAM yöntemi ile post-kor yapımı için farklı teknikler bulunmaktadır; kor ayrı bir şekilde hazırlanıp posta ve dişe simante edilebilir, tek parça post ve kor hazırlanabilir veya kor postun üzerine ısı-basınç tekniği ile şekillendirilebilir. ${ }^{1,12} \mathrm{Bu}$ yöntemlerle hazırla- nan restorasyonların standart, estetik açıdan mükem- mel, hassas uyumlu, hızlı ve yüksek materyal kalitesine sahip olduğu bildirilmiştir. ${ }^{13}$

\section{BANKOĞLU GÜNGÖR, KARAKOCA NEMLİ} DOĞAN, KARADAĞ

Bu vaka sunumunun amacı aşırı madde kaybına uğramış endodontik tedavili maksiller ön dişlerde, tek seansta hem post-kor hem de kron restorasyonun CAD/CAM sistemiyle tamamlandığı estetik restorasyonların sunulmasıdır.

\section{VAKA SUNUMU}

Aşırı madde kaybına uğramış endodontik tedavili maksiller ön bölge dişlerinin restorasyonu talebi ile Gazi Üniversitesi, Diş Hekimliği Fakültesi, Protetik Diş Tedavisi Anabilim Dalı Kliniği' ne başvuran iki hastada, post-kor destekli kron restorasyonların CAD/CAM yöntemiyle tek seansta yapılması planlandı. Dişlerin periapikal radyografik muayenesi sonucu endodontik tedavi yapılmış olduğu ve herhangi bir periapikal patoloji olmadığı gözlendi. Klinik muayene sonucu dişlerin mobilite göstermediği, gingival dokuların sağlıklı olduğu ve kron yapımı için yeterli interoklüzal mesafeye sahip oldukları tespit edildi (Resim 1 ve 2). Hastalara uygulanabilecek tüm tedavi şekilleri detaylıca anlatıldıktan sonra, hastalardan imzalı bilgi- lendirilmiş olur alındı. Her iki hastanın da estetik olarak en iyi restorasyonun mümkün olan en kısa sürede yapılması talepleri bu tedavi yöntemini seçmelerine sebep olmuştur. Kök kanalları radyografide ölçüldü ve kaldırılacak kanal dolgu materyalinin miktarı belirlendi. Post boşlukları post frezleri ile genişletildi ve undercutlar giderildi. Diş üzerindeki keskin kenar ve köşeler dijital ölçü, tasarım ve üretim aşamalarında ortaya çıkabilecek sorunları önlemek amacıyla yuvarlatıldı.

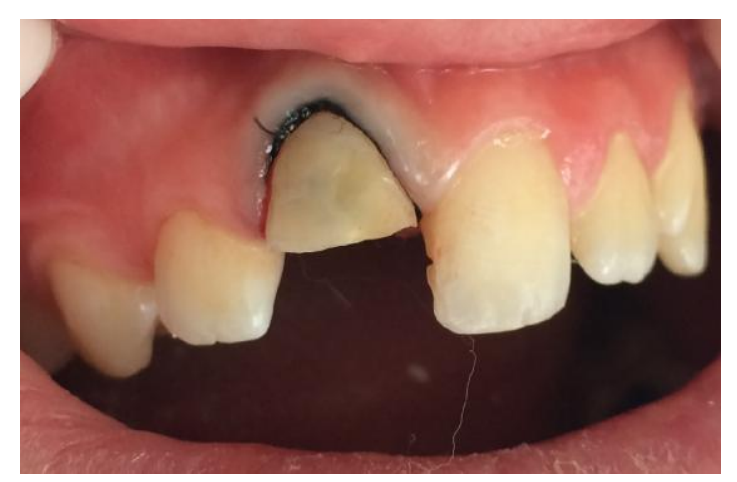

Resim 1. Vaka 1' in restorasyon öncesi ağız içi görünümü. 
Atatürk Üniv. Diş Hek. Fak. Derg.

J Dent Fac Atatürk Uni

Cilt:26, Sayı:1, Yıl: 2016, Sayfa: 133-138

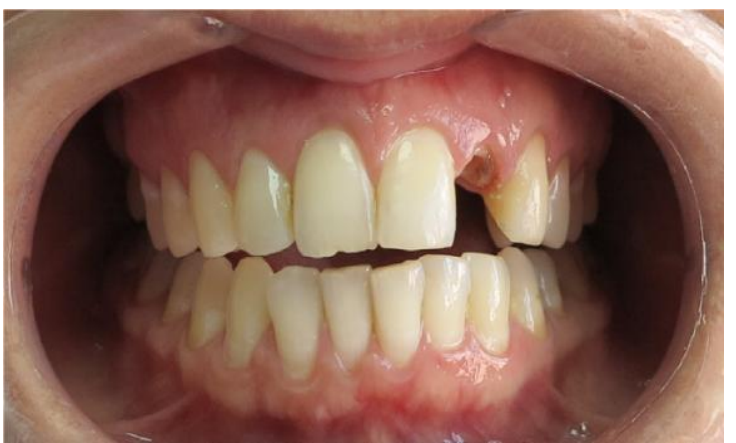

Resim 2. Vaka 2' nin restorasyon öncesi ağız içi görünümü.

\section{VAKA 1}

Sağ üst santral kesici dişin post boşluğunun ölçüsünün alınması esnasında ölçü materyalini desteklemesi amacıyla ince bir bond fırçası kanal içine pattern rezin ile birlikte uyumlandı. Silikon esaslı ölçü maddesi kullanarak (Zeta Plus; Zhermack, Badia Polesine, Italy) çift karıştırma tekniği ile post boşluğu ve maksiler arkın ölçüsü alındı (Resim 3A, 3B ve $3 C$ ). Ölçünün dijital olarak taranması esnasında yansımayı önlemek amacıyla ince ve homojen bir tabaka halinde Cerec Optispray (Sirona, Germany) uygulandı. Ağız dışı bir tarayıcı (inEos X5; Sirona, Germany) ile ölçüler dijital olarak tarandı ve sistemin CAD yazıımına (inLab SW 4.2, Sirona Dental Systems, Bensheim, Germany) aktarılan veriler ile 3 boyutlu modeller elde edildi. Tek parça post-kor restorasyonların üretimi için restorasyon tipi olarak "crown" seçildi. Sanal model üzerinde restorasyonun giriş yolu ve marjinleri belirlendi. Siman film kalınlığı sıfır olarak belirlendi ve undercutlar uzaklaştırıldı. Yazılım tarafından önerilen tasarım üzerinde modifikasyonlar yapıldı. Restorasyonun post-kor bölümü sisteme ait freze ünitesinde (inLab $M C X L$, Sirona Dental Systems, Bensheim, Germany) lityum disilikat esaslı seramik bloktan (IPS e.max CAD inLab MC XL, Sirona Dental Systems, Bensheim, Germany) üretildi ve kristalize edildi. Tek parça post-kor dual polimerize rezin siman (Panavia F 2.0, Kuraray, Japan) ile simante edildi. Tek parça post-kor'un simante edildiği diş ağız içi tarayıcı ile (Omnicam, Sirona Dental Systems, Bensheim, Germany) taranarak dijital kayıtlar CAD/CAM ünitesine transfer edildi. Restore edilecek dişin yer aldığı arkın yanı sıra karşıt ark ve kapanış ilişkisi de taranarak sanal modeller elde edildi. Sanal modeller üzerinde restorasyonun giriş yolu ve marjinleri belirlendi. Tasarlanan restorasyon üzerinde küçük değişiklikler yapıldı, oklüzal ve proksimal kontakları düzenlendi, siman aralığı $50 \mu \mathrm{m}$ olarak
BANKOĞLU GÜNGÖR, KARAKOCA NEMLİ, DOĞAN, KARADAĞ

belirlendi. Lityum disilikat kron, kazıma ünitesinde (inLab MC XL, Sirona Dental Systems, Bensheim, Germany) şekillendirildi. Restorasyonun uyumu, proksimal kontakları ve estetik özellikleri hasta ağzında kontrol edildi (Resim 4A ve 4B). Restorasyon dual polimerize rezin siman (Bifix, Voco, Cuxhaven, Germany) ile simante edildi. Başlangıçta 10 sn ışınlama yapıldıktan sonra taşan simanlar temizlendi. Sonrasında restorasyon her yüzeyden 20 sn olarak ışınlandı. Simantasyon sonrası lityum disilikat restorasyonun sentrik oklüzyon ve lateral gezinmelerde kontakt noktaları kontrol edildi, gerekli uyumlamalar yapıldı (Resim 5). Üretici firmanın talimatları doğrultusunda mekanik polisaj (OptraFine Diamond Polishing System; Ivoclar Vivadent, Schaan, Liechtenstein) uygulandı. Hastanın kron kısmını kaybettiği dişinin kliniğe geldiği seansta üretilip hastaya teslim edilmesi ve restorasyonun estetiği hasta tarafından oldukça memnuniyetle karşılandı. Hasta 1 yıl sonra kontrole çağrıldı. Kontrol seansında hiçbir mekanik ve biyolojik komplikasyona rastlanmadı.

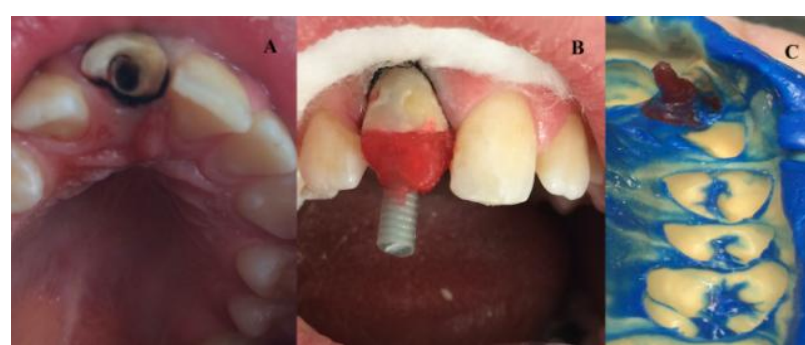

Resim 3. A. Vaka 1' de post kanalının hazırlanması. B. Vaka 1' de plastik bond çubuğunun ve pattern rezinin kanal içerisine uyumlanması. C. Vaka 1' de post boşluğunun ölçüsü.

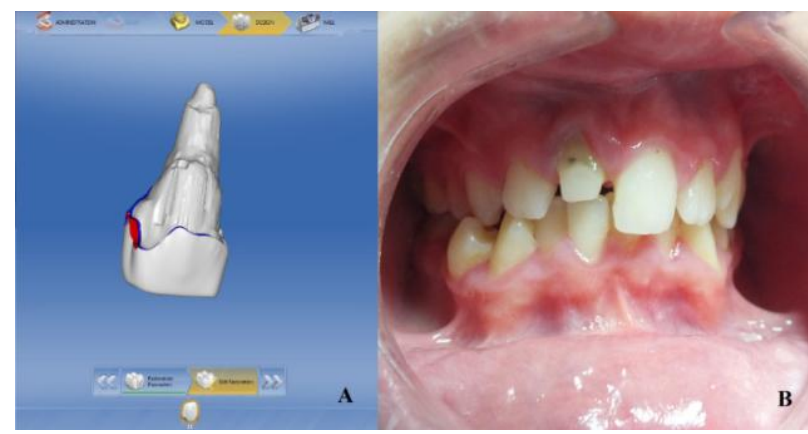

Resim 4. A. Vaka 1' de post ve korun tasarımı. B. Vaka 1' de tasarlanan post ve korun simante edildikten sonra ağız içi görünümü.

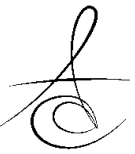




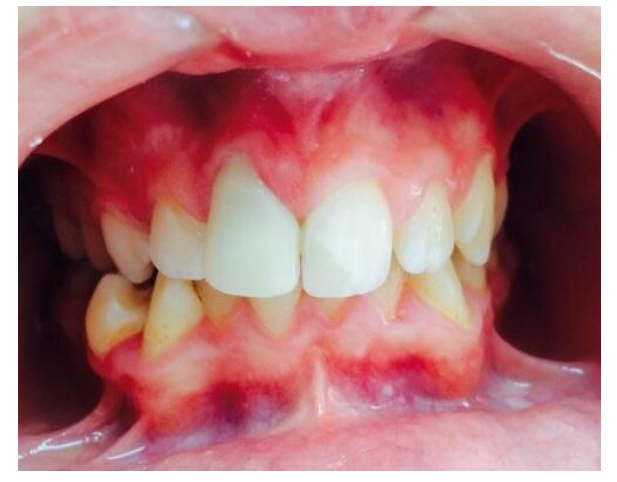

Resim 5. Vaka 1'de tamamlanan restorasyonun ağız içi görünümü.

\section{VAKA 2}

Sol üst lateral kesici dişin kron kısmının tamamen kaybedilmiş ve post boşluğunun oldukça geniş olması sebebiyle direk olarak ağız içi tarama (Cerec Omnicam, Sirona Dental Systems, Bensheim, Germany) ünitesi ile dijital ölçü alınması tercih edildi. Restore edilecek dişin, komşu dişlerin, karşıt dişler ve kapanış ilişkisinin dijital ölçüsü alındı. Sisteme ait yazilım (Cerec SW 4, Sirona Dental Systems, Bensheim, Germany) tarafindan üç boyutlu sanal modeler oluşturuldu. Tasarım modu olarak "Biogeneric Individual" ve restorasyon tipi olarak "Crown Restoration" seçildi. Siman film kalınlığı sıfır olarak belirlendi. Sisteme ait yazilımda (inLab SW 4.2, Sirona Dental Systems, Bensheim, Germany), sanal modeller üzerinde restorasyon marjinleri ve restorasyonun giriş yolu belirlendi ve tasarım yapıldı (Resim 6A, 6B ve 6C). Bazı modifikasyonlar yapılarak tamamlanan tasarım, CAD/CAM sistemi için üretilmiş rezin nanoseramik bloktan (Lava Ultimate Restorative, 3M Espe, St. Paul, USA) sisteme ait aşındırma ünitesinde (inLab MC XL, Sirona Dental Systems, Bensheim, Germany) şekillendirildi. Tek parça post-kor dual polimerize rezin siman (Panavia $\mathrm{F}$ 2.0, Kuraray, Japan) ile simante edildi. Post kısmında polisaj uygulanmadı ve adaptasyon için dokunulmadı. Simantasyon sonrası kor kısmında hiçbir işlem uygulamadan kök kısmı üzerinde ferrule oluş- turmak amacıyla yaklaşık $1 \mathrm{~mm}$ derinliğinde basamak preparasyonu yapıldı. Tek parça post-kor'un simante edildiği diş ağız içi tarayııı ile taranarak dijital kayıtları alındı ve Vaka 1' de anlatıldığı şekilde tek parça postkor üzerine lityum disilikat kron hazırlandı ve simante edildi (Resim 7A ve 7B). 1 yll sonundaki kontrolde mekanik ve biyolojik komplikasyona rastlanmadı.

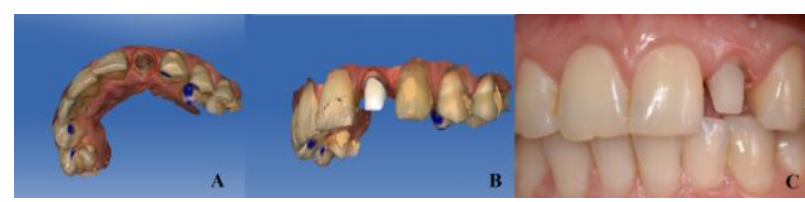

Resim 6. A. Vaka 2' ye ait dijital model. B. Vaka 2' ye ait tasarlanan post-kor restorasyonu. C. Vaka $2^{\prime}$ ye ait tasarlanan post-kor restorasyonunun simantasyon sonrası ağız içi görünümü.

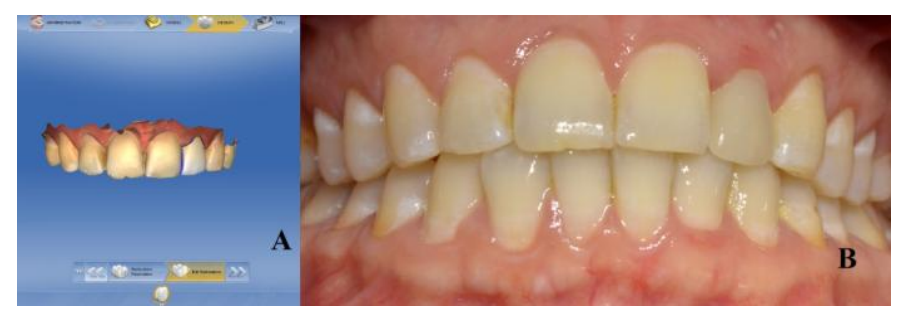

Resim 7. A. Vaka 2' ye at tasarlanan kron restorasyonu. B. Vaka 2' de tamamlanan restorasyonun ağız içi görünümü.

\section{TARTIŞMA}

Aşırı miktarda madde kaybına uğramış endodontik tedavili dişlerin protetik tedavilerinde yeterli koronal diş dokusu bulunmadığı durumlarda restorasyonları desteklemek için kök desteğine intiyaç duyulmaktadır. ${ }^{14,15}$ Bu vakalarda sıklıkla kullanılan post-kor restorasyonlarda post, kor yapıya retansiyon sağlarken kor kısmı da üst restorasyona retansiyon ve stabilite sağlar. ${ }^{16}$ Ancak post yerleştirmek için diş dokularında yapılan preparasyonların diş yapısını zayıflattığı da ortaya koyulmuştur. ${ }^{17,18}$ Bu sebeple kanalın şekil ve boyutuna uygun seçilen postlar; posta iletilen kuvvetin dengeli bir şekilde dağıtılması, daha az dentin kaldırılması sayesinde dişi zayıflatmaması ve postun tutuculuğunun artması gibi avantajları ile dişin ve restorasyonların prognozunu olumlu etkilemektedir. ${ }^{19}$ Çalışmalar endodontik tedavili dişlerdeki başarısızlıkların en önemli nedenlerinden birinin tedaviye bağlı madde kaybı olduğunu göstermiştir. ${ }^{18,20}$ Hastaların artan estetik beklentileri nedeniyle kanalın şekline uygun adaptasyonu sağlayan döküm metal postlar yerini estetik materyallerden üretilen aynı zamanda dayanıkı postlara bırakmaktadır. Bu postlar estetik özellikleri sağlamanın yanı sıra, toksisite ve korozyon riskini azaltmaktadıllar. ${ }^{21} \mathrm{Bu}$ vaka raporunda CAD/CAM sisteminde yeni üretilen seramik materyallerden üretilen post-kor tedavileri anlatılmaktadır. 
Atatürk Üniv. Diş Hek. Fak. Derg.

J Dent Fac Atatürk Uni

Cilt:26, Sayı:1, Yıl: 2016, Sayfa: 133-138
BANKOĞLU GÜNGÖR, KARAKOCA NEMLİ, DOĞAN, KARADAĞ
CAD/CAM sistemleri dental restorasyonların üretim kalitesinin yanı sıra kullanılabilecek estetik mater- yal çeşitliliğinin de artmasına yol açmıştır. ${ }^{15,22}$ Bu materyaller arasında lityum disilikat seramikler mükemmel estetik görünümleri, diş yapısına kuvvetli bağlanmaları ve yüksek mekanik dayanıkılıkları ile çok yaygın olarak kullanılmaktadırlar. ${ }^{23,24}$ Ancak seramik materyallerin sertlikleri, kırılganlıkları ve yüksek elastiklik modulüsleri, son yıllarda fiziksel ve mekanik özellikleri diş dokularına daha yakın olan yeni nesil rezin nanoseramik restoratif materyallerin geliştirilmesine yol açmıştır. ${ }^{25} \mathrm{Bu}$ materyaller yüksek derecede polimerize olmuş rezin bir matriks içine gömülmüş nanoseramik taneciklerinden oluşmaktadır. Rezin nano seramik materyaller bu kompozit yapıları sayesinde dentine yakın elastiklik modülünü gösterirler. ${ }^{26} \mathrm{El}$ Damanhoury ve ark. ${ }^{27}$ aşırı madde kaybına sahip endodontik tedavili dişlerin endokron restorasyonunda kullanılan üç farklı seramiğin (feldspatik porselen, lityum disilikat ve rezin nanoseramik) kırılma direncini değerlendirdikleri çalışmalarında, rezin nano seramiklerin daha yüksek kırılma direnci gösterdiğini fakat mikrosızıntı miktarlarının uzun dönem prognozlarını etkileyebileceğini bildirmişlerdir. Bu vaka raporunda sunulan Vaka 1'de post-kor materyali olarak lityum disilikat, Vaka 2'de ise post-kor materyali olarak rezin nano seramik kullanılmıştır. Her iki vakada da takip süresi sonucunda herhangi bir komplikasyon görülmemesi, CAD/CAM teknolojisi için üretilen bu güncel seramik içerikli materyallerin post-kor restorasyonlarında başarılı bir şekilde kullanılabileceğini düşündürmektedir. Aynı zamanda post ve korun birlikte üretilmesi, post ve korun bağlantısına ilişkin başarısızlıklarında önüne geçmektedir. Tek parça post-kor restorasyonların CAD/CAM sisteminde üretiminde post kanaIının ölçüsü Vaka 1'de olduğu gibi pattern rezinle alınabilmektedir. ${ }^{11}$ Fakat ölçü alımı sırasında pattern rezinin ölçüyle birlikte çıkarılması zor olmakta ve zaman kaybına yol açmaktadır. ${ }^{10}$ Vaka 2'de olduğu gibi post kanalının ve arkın ölçüsünün dijital tarayıcı ile alınması daha pratik bir çözüm yoludur. Böylelikle pattern rezin ve ölçü maddesinin boyutsal değişiminden kaynaklanabilecek sorunlar ortadan kalkmaktadır. Ayrıca geleneksel metotlarla kıyaslandığında daha hassas ve kısa zamanda tamamlanabilen bir yöntemdir. $^{7}$ Bu vaka raporunda her iki yöntemle ölçü alımı da kullanıldı.
Sonuç olarak; CAD/CAM sistemleri post-kor restorasyonlarında başarılı bir şekilde kullanılmaktadır. Bu tekniğin en önemli avantajı ise iyi adaptasyon gösteren restorasyonların tek seansta üretilebilmesidir. Fakat bu sistem için yeni geliştirilen materyallerin postkor restorasyonlarındaki başarısından söz edebilmek için vaka sunumlarının ve in vitro çalışmaların yanı sıra, uzun dönemli klinik çalışmalara da ihtiyaç duyulmaktadır.

\section{KAYNAKLAR}

1. Özcan N, Şahin E. In vitro evaluation of the fracture strength of all-ceramic core materials on zirconium posts. Eur J Dent 2013;7:455-60.

2. Soares CJ, Valdivia AD, da Silva GR, Santana FR, Menezes Mde S. Longitudinal clinical evaluation of post systems: a literature review. Braz Dent ] 2012;23:135-740.

3. Akkayan B, Gulmez T. Resistance to fracture of endodontically treated teeth restored with different post systems. J Prosthet Dent 2002;87:431-7.

4. Faria AC, Rodrigues RC, de Almeida Antunes RP, de Mattos Mda G, Ribeiro RF. Endodontically treated teeth: characteristics and considerations to restore them. J Prosthodont Res 2011;55:69-74.

5. Bittner N, Hill T, Randi A. Evaluation of a one-piece milled zirconia post and core with different postand-core systems: An in vitro study. J Prosthet Dent 2010;103:369-79.

6. Plasmans PJ, Visseren LG, Vrijhoef MM, Kayser AF. In vitro comparison of dowel and core techniques for endodontically treated molars. J Endod 1986;12:382-7.

7. Bosch G, Ender A, Mehl A. A 3-dimensional accuracy analysis of chairside CAD/CAM milling processes. J Prosthet Dent 2014;112:1425-31.

8. Awad MA, Marghalani TY. Fabrication of a custommade ceramic post and core using CAD-CAM technology. J Prosthet Dent 2007;98:161-2.

9. Streacker $A B$, Geissberger $M$. The milled ceramic post and core: $A$ functional and esthetic alternative. J Prosthet Dent 2007;98:486-7.

10. Lee JH. Accelerated techniques for a post and core and a crown restoration with intraoral digital scanners and CAD/CAM and rapid prototyping. J Prosthet Dent 2014;112:1024-9. 
Atatürk Üniv. Diş Hek. Fak. Derg.

] Dent Fac Atatürk Uni

Cilt:26, Sayı:1, Yıl: 2016, Sayfa: 133-138

11. Liu $P$, Deng $X L$, Wang $X Z$. Use of a CAD/CAMfabricated glass fiber post and core to restore fractured anterior teeth: A clinical report. J Prosthet Dent 2010;103:330-3.

12. Butz F, Lennon AM, Heydecke G, Strub JR. Survival rate and fracture strength of endodontically treated maxillary incisors with moderate defects restored with different post-and-core systems: an in vitro study. Int J Prosthodont 2001;14:58-64.

13. Yuksel $E$, Zaimoglu A. Influence of marginal fit and cement types on microleakage of all-ceramic crown systems. Braz Oral Res 2011;25:261-6.

14. Morgano SM, Milot P. Clinical success of cast metal posts and cores. J Prosthet Dent 1993;70:11-6.

15. Çökük N. Endodontik tedavili dişlerde estetik post uygulamaları. Atatürk Üniv Diş Hek Fak Derg 2009;19:124-30.

16. Fernandes AS, Dessai GS. Factors affecting the fracture resistance of post-core reconstructed teeth: a review. Int J Prosthodont 2001;14:355-63.

17. Fokkinga WA, Le Bell AM, Kreulen CM, et al. Ex vivo fracture resistance of direct resin composite complete crowns with and without posts on maxillary premolars. Int Endod J 2005;38:230-7.

18. Trabert KC, Caput AA, Abou-Rass M. Tooth fracture-a comparison of endodontic and restorative treatments. J Endod 1978;4:341-5.

19. Sorensen JA, Engelman MJ. Effect of post adaptation on fracture resistance of endodontically treated teeth. J Prosthet Dent 1990;64:419-24.

20. Rippe MP, Santini MF, Bier CA, Baldissara P, Valandro LF. Effect of root canal preparation, type of endodontic post and mechanical cycling on root fracture strength. J Appl Oral Sci 2014;22:165-73.

21. Ozkurt Z, Iseri U, Kazazoglu E. Zirconia ceramic post systems: a literature review and a case report. Dent Mater J 2010;29:233-45.

22. Ramirez-Sebastia A, Bortolotto T, Roig M, Krejci I. Composite vs ceramic computer-aided design/computer-assisted manufacturing crowns in endodontically treated teeth: analysis of marginal adaptation. Oper Dent 2013;38:663-73.

23. Pissis P. Fabrication of a metal-free ceramic restoration utilizing the monobloc technique. Pract Periodontics Aesthet Dent 1995;7:83-94.
BANKOĞLU GÜNGÖR, KARAKOCA NEMLİ, DOĞAN, KARADAĞ

24. Pieger S, Salman A, Bidra AS. Clinical outcomes of lithium disilicate single crowns and partial fixed dental prostheses: a systematic review. J Prosthet Dent 2014;112:22-30.

25. Chen $C$, Trindade FZ, de Jager N, Kleverlaan $C$ J, Feilzer AJ. The fracture resistance of a CAD/CAM Resin Nano Ceramic (RNC) and a CAD ceramic at different thicknesses. Dent Mater 2014;30:954-62.

26. Koller M, Arnetzl GV, Holly L, Arnetzl G. Lava ultimate resin nano ceramic for CAD/ CAM: customization case study. Int J Comput Dent 2012;15:159-64.

27. El-Damanhoury $\mathrm{H}$, Haj-Ali R, Platt J. Fracture Resistance and Microleakage of Endocrowns Utilizing Three CAD-CAM Blocks. Oper Dent 2015;40:201-10.

\section{Yazışma Adresi}

Dr. Merve Bankoğlu Güngör

Gazi Üniversitesi, Diş Hekimliği Fakültesi, Protetik Diş Tedavisi Anabilim Dalı Emek 8.cad Ankara

Tel: 03122034196

e-mail: mervebankoglu@yahoo.com 